\title{
Determinants of Library Subscription Prices of Economic Journals
}

\author{
Sumiko Asai \\ School of Political Science and Economics, Meiji University, Tokyo, Japan \\ Email address: \\ asai@meiji.ac.jp

\section{To cite this article:} \\ Sumiko Asai. Determinants of Library Subscription Prices of Economic Journals. International Journal of Economics, Finance and \\ Management Sciences. Vol. 6, No. 1, 2018, pp. 1-5. doi: 10.11648/j.ijefm.20180601.11
}

Received: October 9, 2017; Accepted: October 31, 2017; Published: December 20, 2017

\begin{abstract}
Although an increase in the prices of academic journals across several decades has been a crucial issue for research institutions, few studies using individual journal prices have been carried out on the introduction of a bundling service called Big Deal. The present study empirically examines the determinants of the prices of 409 economic journals using the latest data. The results found that publishers set higher prices for more frequently cited journals, implying that the demand factor influences the price level in addition to cost factors. Furthermore, prices of journals published by large commercial publishers are higher than those published by professional associations and university presses. However, the prices differ among large commercial publishers, and further investigation is needed to conclude whether they set higher prices by exercising market power. On the other hand, an increase in the number of pages in individual journals caused by an increase in the number of submitted articles certainly leads to a corresponding rise in journal subscription prices. The healthy development of open access journals to ensure that everyone can read articles for free is needed to restrict an increase in the prices of traditional subscription journals.
\end{abstract}

Keywords: Economic Journal, Price, Citation

\section{Introduction}

For several decades, the increase in subscription prices of academic journals has been an important topic of intense debates among academic circles. Although empirical studies using individual journal subscription prices were carried out often in the 1990s, the topic has not been explored recently. However, [1], while discussing academic journals from various viewpoints, also referred to an increase in prices of subscription journals. Serial crisis remains a topic to be investigated.

The main reason for the scarcity of related price research is the introduction of Big Deal contracts by large publishers, such as Elsevier. These Big Deal contracts enable users to access and download all the articles published electronically under the condition that research institutions continue to purchase the printed journals to which they have subscribed. In other words, publishers create a bundle of electronic journals and then link this bundle to the printed journals. With the introduction of the Big Deal bundling service, the subscription price for a single journal has gradually become unimportant. However, the cost of the Big Deal service increases in proportion to the increase in journal subscription prices, because the payments for Big Deal contracts are calculated based on the prices of the journals to which research institutions subscribe. [2] calculated bundle price per citation by publisher and research institution to evaluate Big Deal services and found that the variations of price per citation among publishers and research institutions are large. The results imply that the balance between benefits and costs of Big Deal services differs among research institutions. Recently, several research institutions terminated their Big Deal contracts in consideration of the balance between the benefits gained from access to many journals and the increasing costs. The research institutions that returned to purchasing individual journals need to select them from the viewpoint of the balance between actual need and price. Therefore, the interest in individual journal prices has recently started increasing again.

[3] stated that a bundled price-setting approach creates a substantial barrier to entry, and that the increased concentration in the academic journal market might lead to a rise in prices of journals published by large commercial publishers. [4] estimated journal subscription prices across a 
wide range of fields to examine the relationship between the price and the share of large publishers in each field. Because market concentration has increased with the development of Big Deal contracts, the relationship between price level and market power needs to be analyzed and discussed in depth. Therefore, the present study employs the latest data to estimate journal subscription prices for libraries and identify their determinants, as well as the price differences by type of publisher. The results may provide an explanation for the increase in journal subscription prices.

Although most empirical studies on journal prices were conducted before the introduction of electronic publishing, recent price-setting approaches for academic journals have become diversified, in addition to the Big Deal, with the development of electronic journals. One main price-setting approach is that publishers offer research institutions the choice to purchase only printed journals, only electronic journals, or both formats for individual titles. The prices of printed and electronic formats differ among publishers. To give an example, the prices for printed and electronic formats published by Wiley are the same, whereas prices of electronic journals distributed by Sage are lower than the printed format prices by 8 percent, according to their price lists. The edition costs of journals are generally large, although print and electronic distribution costs are small. In other words, the common costs for printed and electronic journals are large, whereas specific costs for each format are small. Therefore, this small price difference implies that publishers set prices for printed and electronic journals based on a standalone cost.

The other main price-setting approach is that publishers create a bundle of printed and electronic formats for individual journals, and provide both formats in the bundled service. A large publisher, Taylor, usually offers research institutions two choices: either only the electronic journal format or a bundle of both printed and electronic formats. The option of subscribing to only the printed format has not been provided for research institutions. In addition, Springer has generally combined printed and electronic journal formats into one package, and subscribers are not provided with an option of choosing either only the printed format or the electronic one for many journals.

Although the price-setting approach may influence the individual printed journal prices, the determinants of prices of printed journals included in bundling services have not been investigated. Thus, the present study empirically examines the price determinants of printed subscription journals for libraries, taking into account the bundling of the two formats.

\section{Literature Review}

Recent studies on scholarly communication mainly deal with the evaluation of Big Deal services and open access journals, whereas empirical studies using individual prices of subscription journals have not been carried out since [4]. Previous empirical studies on journal subscription prices can be categorized into three types: price discrimination between personal and library subscriptions, relationship between publisher's conduct and journal prices, and determinants of library prices, which the present study investigates.

Regarding price discrimination, [5] compared library and personal prices for 89 academic journals in 1974 and 1984 . They found that the average library price was more than twice the personal price in 1974, and that this difference increased in 1984. [6] estimated the ratios of library prices to personal prices using the number of citations by ordinary least squares, and reported a positive estimated value for the citation count in the price ratio equation. [6] concluded that the high prices of the more frequently cited journals compensate for lost subscription revenues caused by users who do not purchase journals personally, but rather copy the relevant articles from libraries.

With regard to the relationship between publisher's conduct and journal prices, [7] examined the impact of mergers between academic publishers on journal prices using a differences-in-differences approach, and reported that mergers are generally associated with price increases.

As for the determinants of library prices, [8] employed ordinary least squares to estimate the subscription prices of academic journals for libraries using variables such as the number of issues, advertising, number of pages, type of publisher, and academic field. [8] reported that library prices of journals published by commercial publishers are higher than those by nonprofit associations. [9] added the citation count of journals and the number of copies per issue to the independent variables used by [8] to estimate the economic journal prices. [9] reported that the prices of more frequently cited journals are higher, and the negative coefficient for the number of copies reflects the economies of scale in journal publishing. [10] also estimated the library prices of economic journals using variables measuring journal cost, citation count, and type of publisher. They found that the coefficient of the frequency of citation is positive, but not significant at the 10 percent significance level. [4] considered the endogeneity between prices and citations, and then estimated the journal prices for libraries using instrumental variables, although they did not report the result of the endogeneity test. [4] concluded that commercial publishers set higher prices than professional associations, and that the number of citations has a positive impact on prices. Further, they found that prices are positively correlated with the degree of market concentration calculated as the number of journal titles across academic fields.

\section{Model and Data}

The present study examined 409 economic journals, extracted from Elsevier's database called Scopus, which was released in 2017. Journals for which price information was not available were excluded from the analysis. All journals are written in English, and have at least one citation a year since 2011. The journals are largely classified into five categories by type of publisher: (a) journals edited and published by five large commercial publishers called the Big 5 (Elsevier, Springer, Taylor, Wiley, and Sage); (b) journals edited by professional associations and published by commercial publishers, such as Wiley; (c) journals edited and published by 
professional associations; (d) journals edited and published by university presses, such as Oxford University Press; and (e) journals published by small- or medium-sized publishers other than the abovementioned four types.

Table 1 provides some descriptive statistics by type of publisher. Journals edited and published by five large commercial publishers (type a) account for 60 percent of the 409 titles; journals edited by professional associations and published by commercial publishers (type b) include 55 titles (13.4 percent); those edited and published by professional associations (type c) include 20 journals (4.9 percent); those edited and published by university presses (type d) include 48 titles (11.7 percent); and finally, the journals published by small- or medium-sized commercial publishers (type e) include 41 titles (10.0 percent). Furthermore, journal subscriptions sold in a bundle of printed and electronic formats, and which do not provide research institutions with an option to purchase the printed format only, include 143 titles (35.0 percent). This shows that the bundling of the two formats for individual titles has penetrated the economic journals market.

The average price in our sample is 1,064 US dollars. However, whereas the average price for the journals edited and published by five large commercial publishers is 1,313 US dollars, that for journals edited by professional associations and published by commercial publishers is 592 US dollars. This highlights that the price difference across different types of publisher might be large.

Table 1 shows that the average number of pages was 905 in 2016, indicating that economic journals are voluminous publications. [11] reported that the average number of pages for 10 highly cited economic journals published by nonprofit organizations increased from 1,384 pages in 1985 to 1,637 pages in 2001, whereas that for 10 economic journals published by commercial publishers increased significantly from 913 in 1985 to 1,700 in 2001 . The number of pages in the journals published by nonprofit organizations selected by [11] was 1,897 in 2016 , and that by commercial publishers was 1,824 in the same year, showing that the number of pages continues to increase.

In Table 1, cite 16, referred to as the cite score in the Scopus database, is defined as the number of citations in 2016 divided by the number of documents published from 2013 to 2015 . Journals edited and published by professional associations had the highest cite score.

Table 1. Descriptive Statistics of the 409 Economic Journals in the Sample.

\begin{tabular}{|c|c|c|c|c|c|c|}
\hline & \multicolumn{2}{|c|}{ price (US dollars) } & \multicolumn{2}{|l|}{ page } & \multicolumn{2}{|l|}{ cite16 } \\
\hline & Average & C.V. $(\%)$ & Average & C.V. $(\%)$ & Average & C.V. (\%) \\
\hline Type a & 1,313 & 74.45 & 938 & 81.58 & 1.52 & 79.87 \\
\hline Type b & 592 & 52.40 & 836 & 63.51 & 1.32 & 94.15 \\
\hline Type c & 661 & 73.54 & 943 & 88.78 & 2.37 & 95.50 \\
\hline Type d & 608 & 53.61 & 1,010 & 62.60 & 2.11 & 74.81 \\
\hline Type e & 934 & 88.44 & 655 & 74.26 & 0.89 & 108.76 \\
\hline Total & 1,064 & 82.82 & 905 & 78.04 & 1.55 & 87.61 \\
\hline
\end{tabular}

C.V.: Coefficient of Variation (\%)

Type a: Journals edited and published by five large commercial publishers

Type b: Journals edited by professional associations and published by commercial publishers

Type c: Journals edited and published by professional associations

Type d: Journals edited and published by university presses

Type e: Journals published by small-medium-sized commercial publishers, other than the abovementioned four types

The present study estimates the prices as specified in equation (1), where ln denotes the natural logarithm.

$$
\begin{array}{r}
\text { lnprice }=\alpha_{0}+\alpha_{1} \text { lnpage }+\alpha_{2} \text { lnissue }+\alpha_{3} \text { lnyear }+\alpha_{4} \text { lncite } 16+\alpha_{5} \text { bundle }+\alpha_{6} \text { Elsevier }+\alpha_{7} \text { Springer }+ \\
\alpha_{8} \text { Taylor }+\alpha_{9} \text { Wiley }+\alpha_{10} \text { Sage }+\alpha_{11} \text { mixture }+\alpha_{12} \text { association }+\alpha_{13} \text { university }
\end{array}
$$

The dependent variable price denotes the library subscription price in US dollars for individual journals in 2017. The independent variables page and issue denote the total number of pages and issues for a journal in 2016, respectively. The variable year denotes the number of years since the journal was established. Although Table 1 refers to five large commercial publishers as one category (type a), in equation (1) they are considered as separated dummy variables, because two-third journals are published by these five publishers with seemingly different price-setting approaches. The variable Elsevier is set to 1 if the journal is published by Elsevier, and is 0 otherwise. Similarly, the variable Springer is set to 1 if the journal is published by Springer, and is 0 otherwise. The variables identifying the other three commercial publishers (Taylor, Wiley, and Sage) are defined in an analogous way. The variable mixture is set to 1 if the journal is edited by a professional association and published by a private publisher, and is 0 otherwise. The variable association is set to 1 if the journal is edited and published by a professional association, and is 0 otherwise. The variable university is set to 1 if the journal is edited and published by a university press, and is 0 otherwise.

The Scopus database provides the cite score, which is defined as the number of citations in a year divided by the number of documents published in the previous three years. As shown in Table 1, the cite score in 2016 is referred to as cite 16 in the price equation. To consider the possibility of endogeneity between prices and citations, [4] estimated the price equation using instrumental variables such as lagged citations and age of the journal. The present study also estimates the price equation (1) by two-stage least squares using instrumental variables that include all the exogenous variables and the past cite scores from 2011 to 2015. The 
number of citations in 2011 divided by the number of documents from 2008 to 2010 is referred to as cite11. The instrumental variables cite12, cite13, cite14, and cite15 are calculated similarly.

The number of circulations for an individual journal is not used as an independent variable, because the data are not available as [11] pointed out. The variable bundle is set to 1 if the journal is provided as a bundle of printed and electronic formats without the option of having the printed format only, and is 0 otherwise. While the variables denoting page, issue, citation, and publisher type are often used in previous empirical studies, this work is the first to employ the variable bundle.

Table 2 shows the correlation coefficients between the independent variables excluding the dummy variables. The correlation coefficient between the variables price and page is positive at 0.476 , as expected. The correlation between the variables price and issue is higher than that between price and page, reflecting that the subscription price includes carriage charges for each issue. The correlation coefficient between the variables price and cite 16 is small at 0.147 , although the null hypothesis is rejected at the 1 percent significance level.

As for the instrumental variables, while the Spearman's rank correlation coefficient between cite 11 and cite 12 is very high at 0.945 , that between citell and citel6 is 0.856 . Although the journals cited frequently in the past are frequently cited at present as well, the ranking changes to some degree across years.

Table 2. Correlation Coefficients.

\begin{tabular}{lllll}
\hline & price & page & issue & cite16 \\
\hline price & 1.000 & & & \\
page & 0.476 & 1.000 & & \\
issue & 0.664 & 0.649 & 1.000 & \\
cite16 & 0.147 & 0.365 & 0.246 & 1.000 \\
\hline
\end{tabular}

\section{Estimation Results}

The present study estimates the price equation (1) using the instrumental variables - all independent variables and the past cite scores-by two-stage least squares, and tests the endogeneity between the variables price and citel6 using the Hausman test. As a result, the null hypothesis that the variables price and cite16 are exogenous is not rejected at the 10 percent significance level. Therefore, the price equation is estimated by ordinary least squares as well. As highlighted in Table 3, the estimated values are almost the same.

The estimated coefficients of the variables page and issue are positive, as expected, and significant at the 5 percent and 1 percent significance levels, respectively. The estimated coefficient value for the variable cite 16 is positive, implying that subscribers may have a high willingness to pay for more frequently cited journals; therefore, publishers set higher prices. On the other hand, [9] estimated the price equation using the number of copies per issue, and reported that the estimated coefficient for the number of copies was negative at the 5 percent significance level. The result of [9] implies the presence of economies of scale in the journal publishing industry. Although the present study does not use the number of copies as an independent variable because of data unavailability, the positive effect of the willingness to pay and the negative effect caused by the economies of scale may bring about an insignificant positive coefficient value for the variable cite 16.

The four estimated coefficient values for large commercial publishers, excluding the variable Sage, are positive and significant at the 1 percent or 10 percent significance levels, implying that the subscription prices of journals published by these publishers are relatively high. Taylor sets bundled prices of printed and electronic formats for libraries, and the prices of many journals published by Springer also refer to combined formats, whereas the prices established by Elsevier, Wiley, and Sage are for printed journals only. Although the three estimated coefficient values for Elsevier, Taylor, and Wiley are almost the same, the prices of journals published by Taylor are generally lower than those of Elsevier and Wiley, because the estimated coefficient values for the variable bundle are negative $(-0.1124$ or -0.1148$)$.

The prices of journals edited and published by professional associations and university presses are low, because the estimated coefficient values for the variable association and university are negative at the 1 percent significance level.

Table 3. Estimation Results.

\begin{tabular}{lcc}
\hline & $\begin{array}{l}\text { Two-stage Least } \\
\text { Squares }\end{array}$ & $\begin{array}{l}\text { Ordinary Least } \\
\text { Squares }\end{array}$ \\
\hline$\alpha_{0}$ (constant) & $4.9209(0.3093)^{* * *}$ & $4.9583(0.2962)^{* * * *}$ \\
$\alpha_{1}$ (page) & $0.1159(0.0529)^{* *}$ & $0.1115(0.0519)^{* *}$ \\
$\alpha_{2}$ (issue) & $0.7286(0.0750)^{* * *}$ & $0.7280(0.0750)^{* * *}$ \\
$\alpha_{3}$ (year) & $-0.0331(0.0443)$ & $-0.0340(0.0442)$ \\
$\alpha_{4}$ (cite16) & $0.0021(0.0419)$ & $0.0123(0.0342)$ \\
$\alpha_{5}$ (bundle) & $-0.1124(0.0786)$ & $-0.1148(0.0784)$ \\
$\alpha_{6}$ (Elsevier) & $0.3609(0.1090)^{* * *}$ & $0.3522(0.1069)^{* * *}$ \\
$\alpha_{7}$ (Springer) & $0.1862(0.1111)^{*}$ & $0.1846(0.1110)^{*}$ \\
$\alpha_{8}$ (Taylor) & $0.3574(0.1254)^{* * *}$ & $0.3557(0.1252)^{* * *}$ \\
$\alpha_{9}$ (Wiley) & $0.3262(0.1206)^{* * *}$ & $0.3213(0.1200)^{* * *}$ \\
$\alpha_{10}$ (Sage) & $0.0020(0.1283)$ & $-0.0024(0.1278)$ \\
$\alpha_{11}$ (mixture) & $-0.2555(0.1094)^{* *}$ & $-0.2585(0.1091)^{* *}$ \\
$\alpha_{12}$ (association) & $-0.3899(0.1381)^{* * *}$ & $-0.3963(0.1372)^{* * *}$ \\
$\alpha_{13}$ (university) & $-0.3295(0.1149)^{* * *}$ & $-0.3377(0.1132)^{* * *}$ \\
adjusted ${ }^{2}$ & 0.5284 & 0.5285 \\
\hline
\end{tabular}

$* * *, * *$, and $*$ denote the $1 \%, 5 \%$, and $10 \%$ significance levels.

The standard errors are denoted in parentheses.

\section{Discussion}

The present study found that the prices of journals published by professional associations and university presses are low, whereas large commercial publishers tend to set high prices. However, the Japanese Economic Association, which has edited a journal titled the Japanese Economic Review published by Wiley, has spent 17 million yen (about 150,000 US dollars) per year in producing the journal. In this context, the professional associations collect member fees, and part of the revenues are generally used to publish journals. Some university presses may be subsidized by universities to produce publications, although the expenditure data are not available. In contrast, commercial 
publishers produce their publications without any subsidy. Overall, we need to consider the characteristics of publisher types while making price comparisons.

[4] claimed that publishers with a large share (calculated as the number of journal titles) tend to set high prices. In the present study, the coefficient value for Elsevier is high among the Big 5, and the number of journals published by Elsevier is the largest (80 titles). In contrast, the coefficient value for the variable Springer is relatively low, whereas Springer is second to Elsevier with 68 journal titles. As for economic journals, publishers with large shares do not always set higher prices. Although the present study found that large commercial publishers set high prices, we cannot infer that publishers set a high markup by exercising market power.

However, according to the financial report of John Wiley \& Sons, the ratio of the profit to revenues in the journal sector reached 30.5 percent in 2016. [1] reported that the financial reviews of the other large commercial publishers show similar patterns. Since large commercial publishers have achieved high margin rates in the subscription journal section, the criticism of libraries about the continual increase in journal subscription prices is understandable. Therefore, the commercial publishers have accountability for an increase in prices.

Previous studies reported that the price of a journal with more pages is higher, and the present study reaches an analogous conclusion. Because the number of pages in an individual journal tends to increase, such increase may justify the corresponding rise in the journal price. Since researchers are evaluated based on the number of articles published in prestigious journals, the number of articles submitted to academic journals has increased. With the increase in the number of submitted articles, publishers or journal editors increase the number of pages for individual journals, which eventually increases the subscription price. One method to address this problem is to develop open access journals. If prominent open access journals would develop, the increase in the number of pages in traditional subscription journals could be controlled, which may lead to restrain further increases in journal prices.

\section{Conclusion}

The present study found that, in addition to cost-related factors, demand influences the price level. It is also shown that large commercial publishers set higher subscription prices for their journals, although further investigation is needed to conclude whether they exercise market power while setting prices.

Furthermore, one reason for the continuous rise in journal prices is the increase in the number of pages in a subscription journal. Open access journals may contribute to restrain the number of pages of subscription journals, despite the steady increase in the number of submitted articles. However, although quality differs among traditional subscription journals, many researchers recognize that the variation in quality among open access journals is also large. A healthy development of open access journals is needed to foster knowledge sharing in academic circles and control subscription journal prices. However, despite open access journals responding to an increase in the supply of articles, this increased supply may in turn lead to an increase in journals with few readers, if the time researchers spend on reading articles is constant or does not increase remarkably. A decrease in circulation numbers of individual subscription journals may lead to a rise in their prices. In this sense, the root cause of serial crises may be the evaluation system of researchers based on the number of referred articles. However, the present study estimated the journal subscription prices in 2017 only, and thus, in order to corroborate the findings, we need to keep monitoring the number of submitted articles as well as subscription prices in the future.

\section{Acknowledgements}

This work was supported by JSPS KAKENHI Grant Number 15K03470.

\section{References}

[1] Greco, A. N. (2015). Academic libraries and the economics of scholarly publishing in the twenty-first century: Portfolio theory, product differentiation, economic rent, perfect price discrimination, and the cost of prestige. Journal of Scholarly Publishing, 47 (1), 1-43.

[2] Bergstrom, T. C., Courant, P. N., McAfee, R. P. and Williams, M. A. (2014). Evaluating big deal journal bundles. Proceedings of the National Academy of Sciences of the United States of America, 111 (26), 9425-9430.

[3] Edlin, A. S. and Rubinfeld, D. L. (2005). The bundling of academic journals. American Economic Review, 95 (2), $441-$ 446.

[4] Dewatripont, M., Legros, P., Ginsburgh, V., and Walckiers, A. (2007). Pricing of scientific journals and market power. Journal of European Economic Association, 5 (2-3), 400-410.

[5] Joyce, P. and Merz, T. E. (1985). Price discrimination in academic journals. Library Quarterly, 55 (3), 273-283.

[6] Liebowitz, S. J. (1985). Copying and indirect appropriability: Photocopying of journals. Journal of Political Economy, 93 (5), 945-957.

[7] McCabe, M. J. (2002). Journal pricing and mergers: A portfolio approach. American Economic Review, 92 (1), 259-269.

[8] Petersen, H. C. (1990). University libraries and pricing practices by publishers of scholarly journals. Research in Higher Education, 31 (4), 307-314.

[9] Petersen, H. C. (1992). The economics of economics journals: A statistical analysis of pricing practices by publishers. College \& Research Libraries, 53 (2), 176-181.

[10] Chressanthis, G. A. and Chressanthis, J. D. (1994). The determinants of library subscription prices of the top-ranked economics journals: An econometric analysis. Journal of Economic Education, 25 (4), 367-382.

[11] Bergstrom, T. C. (2001). Free labor for costly journals? Journal of Economic Perspectives, 15 (3), 183-198. 